\title{
On the Possibility of Using Renewable Energy Sources for Operation of Microwave Convective Drying of Grain
}

\author{
Dmitry Budnikov* \\ Federal State Budgetary Scientific Institution "Federal Scientific Agroengineering Center VIM", \\ Moscow, Russia
}

\begin{abstract}
Currently, the power supply of agricultural enterprises should be designed considering not only the required installed capacity but also the peculiarities of production. Thus, the presence of livestock operations implies waste, the disposal of which entails costs. At the same time, feed preparation, including drying of fodder grain is associated with significant energy costs. Thus, the availability of biogas equipment will allow the synthesis of utilization technologies in the form of processing into biogas and the energy supply of equipment to carry out drying. At the same time, attention should be paid to technologies with reduced energy consumption for technological processes. For example, microwave convective or infrared convective drying of grain. These technologies have a reduced energy consumption for moisture removal, but the installed capacity of the equipment is higher than in traditional technologies. This work is aimed at investigating the ratio of heat and electric energy expended in the process of microwave convective drying and the choice of possible renewable energy sources for the implementation of technological operations. Considering that drying of grain is mainly carried out during the harvesting period before storing, it allows considering energy equipment as a source of thermal energy in the cold period, when drying is not required.
\end{abstract}

\section{Introduction}

The power supply of agricultural production objects both at the design and reconstruction stages is associated with the study of technological processes and operations of a given farm. The implemented projects should be based on the energy balance of both the implemented product technologies and energy generation [1]. Synthesis of various existing generation and waste disposal technologies allows significantly reducing the cost of the final product. Drying can be considered an example of one of the energy-intensive processes in agricultural production since the energy intensity of agricultural production is largely related to the cultivation of crops. The gross harvest of cereals in the world is currently at 2 billion tons per year. However, several processes require substantial energy inputs to process the harvested crops. One of the obligatory and, at the same time, energy-intensive processes is drying of grain to bring it to condition moisture [2-4]. As one of the main technological stages of grain

\footnotetext{
*Corresponding author: dimm13@inbox.ru
} 
processing, drying is primarily characteristic of regions characterized by unsatisfactory weather conditions. Even though the main, by volume, producers of cereals are the countries with soft conditions, about $30-40 \%$ of the gross harvest of cereals is subjected to drying.

In some regions, grain drying facilities are not required every year, but only once every 2-3 years. At the same time, the energy intensity of drying cereals is very high and amounts to 3.5-14 MJ for evaporation of one kilogram of moisture [4, 5]. It should be taken into account that many developers such as Petkus (Germany), Cimbria (Denmark), Dozagrant (RF), AVG (RF), Stela Laxhuber GMBH (Germany), Tornum (Sweden), Altinbilek (Turkey), and some others provide data only on heat carrier flow rate for drying or indicate basic capacity and do not provide data for detailed analysis of energy intensity of drying. This is largely due to the influence of weather conditions under which the grain is processed and the condition of the harvested crop. It should also be noted that both grain harvesting and drying in most cases take place in the warm season, which makes it possible to consider idle energy sources as sources of heat.

Existing drying technologies that are currently being developed, such as infrared radiation and microwave fields, have a lower energy cost of 2.8-4.5 MJ for evaporation of one kilogram of moisture compared to classic thermal drying methods [5]. However, if they are used, the share of electrical energy in the total balance of energy costs increases. At the same time, in the literature, there are works devoted to the use of renewable energy sources, such as solar energy, to prepare the drying agent and reduce the cost of drying grain [6, 7]. Both existing and developed plants often allow for both types of energy [8-15], making it possible to consider them as energy plants for grain drying technology. In addition, these plants can be used to provide heat and electricity for technological operations at the plant. These operations can include both decontamination and fodder preparation as well as the provision of domestic needs.

Thus, this work aims to assess the possibility of using renewable energy sources for the implementation of grain drying. For this purpose, the following tasks are fulfilled: experimental estimation of electric and heat energy balance and wheat grain drying in UHF convective drying installation; selection of possible power installations based on renewable energy sources for grain drying.

\section{Materials and Methods}

\subsection{Technologies for Grain Drying Intensification}

Any attempt to increase the productivity of grain drying equipment will involve the capital expenditure on new equipment, improvements to existing equipment, or optimization of grain processing lines. Thus, first of all, we should strive to develop technologies and use of technological equipment, providing the maximum reduction of unit costs for drying of grain material while maintaining within given limits of its quality indicators. I.e., attention should be paid not only to physical-chemical and technological regularities but also to economic indicators, which are basic for farms.

The productivity of grain drying equipment can be increased by increasing the number and geometric dimensions of the apparatus and intensification through external factors $[2,5$, 16]. Reducing the energy intensity of the drying process of grain is possible through the use of electrophysical factors. Such factors include using as a drying agent ozone-air mixture with different concentrations of ozone, a saturation of drying agent with aeroions of different polarity and with different concentrations, use of ultrasound, infrared heating, high frequency, and microwave fields. 
To determine the most promising direction of research into the development of grain drying equipment, we will consider some options for applying electrical technology on existing and developed equipment. Table 1 shows some indicators of grain drying technologies.

Table 1. Technologies of grain drying.

\begin{tabular}{|c|c|c|c|c|}
\hline Technology & $\begin{array}{l}\text { Energy } \\
\text { intensity, } \\
\text { MJ/kg of } \\
\text { moisture }\end{array}$ & $\begin{array}{l}\text { Production } \\
\text { capacity, } t / h\end{array}$ & Execution & Advantages \\
\hline $\begin{array}{l}\text { Classic heat } \\
\text { drying }\end{array}$ & $5-14$ & $4-250$ & $\begin{array}{l}\text { stationary; } \\
\text { mobile }\end{array}$ & high output range \\
\hline Ultrasound & $4.0-6.0$ & $0.01-0.1$ & laboratory & $\begin{array}{l}\text { high intensity of the } \\
\text { moisture transfer } \\
\text { process }\end{array}$ \\
\hline Ozone & $3.5-5.5$ & $0.1-5.0$ & $\begin{array}{c}\text { Containerized, } \\
\text { stationary, } \\
\text { mobile }\end{array}$ & $\begin{array}{l}\text { low power } \\
\text { consumption; } \\
\text { decontamination }\end{array}$ \\
\hline Aeroions & $3.3-5.0$ & $0.1-1.0$ & $\begin{array}{l}\text { stationary; } \\
\text { laboratory }\end{array}$ & low energy density \\
\hline $\begin{array}{l}\text { Radiofrequency } \\
\text { drying }\end{array}$ & $4.5-6.5$ & $0.1-1.0$ & laboratory & $\begin{array}{l}\text { disinfection; } \\
\text { increases the shelf } \\
\text { life of the final } \\
\text { product; }\end{array}$ \\
\hline $\begin{array}{l}\text { Infrared } \\
\text { radiation }\end{array}$ & $5.0-9.0$ & $0.1-10.0$ & $\begin{array}{l}\text { stationary; } \\
\text { laboratory }\end{array}$ & $\begin{array}{ll}\text { high } & \text { heating } \\
\text { intensity; } & \end{array}$ \\
\hline
\end{tabular}

All mentioned intensification of heat and moisture transfer processes requires additional energy capacities. However, the balance of heat and electricity capacity may change significantly. So in the case of drying in a mine dryer with the productivity of 5 tons per hour, it is used the heat generator with a thermal capacity $440-500 \mathrm{~kW}$ at an installed electric power of equipment of $12 \mathrm{~kW}$. In our case we consider the microwave convective drying unit for grain, allowing the user to intensify heat and moisture transfer, to carry out both preparation of the drying agent and direct heating of the grain mass.

\subsection{Laboratory Installation}

The technological scheme in Fig. 1 shows the laboratory installation, which was used for experimental research. This installation contains 6 microwave field sources $(2.45 \mathrm{GHz}$ magnetrons, $700 \mathrm{~W}$ ). The technological process and energy consumption are controlled via the SCADA system with logging and visual presentation to the operator. In addition to the electricity consumption, the current temperatures of the grain layer in the drying zone are displayed to prevent process disturbances. The connection is made via a common meter that records the total process costs by which the energy intensity of the entire machining process per unit of output is evaluated. At the same time, additional control on the required items has been introduced in order to estimate the costs attributable to the power supply of individual electrical consumers, especially sources of electrophysical effects. This makes it possible to determine the workload and the correct selection of individual assemblies. 


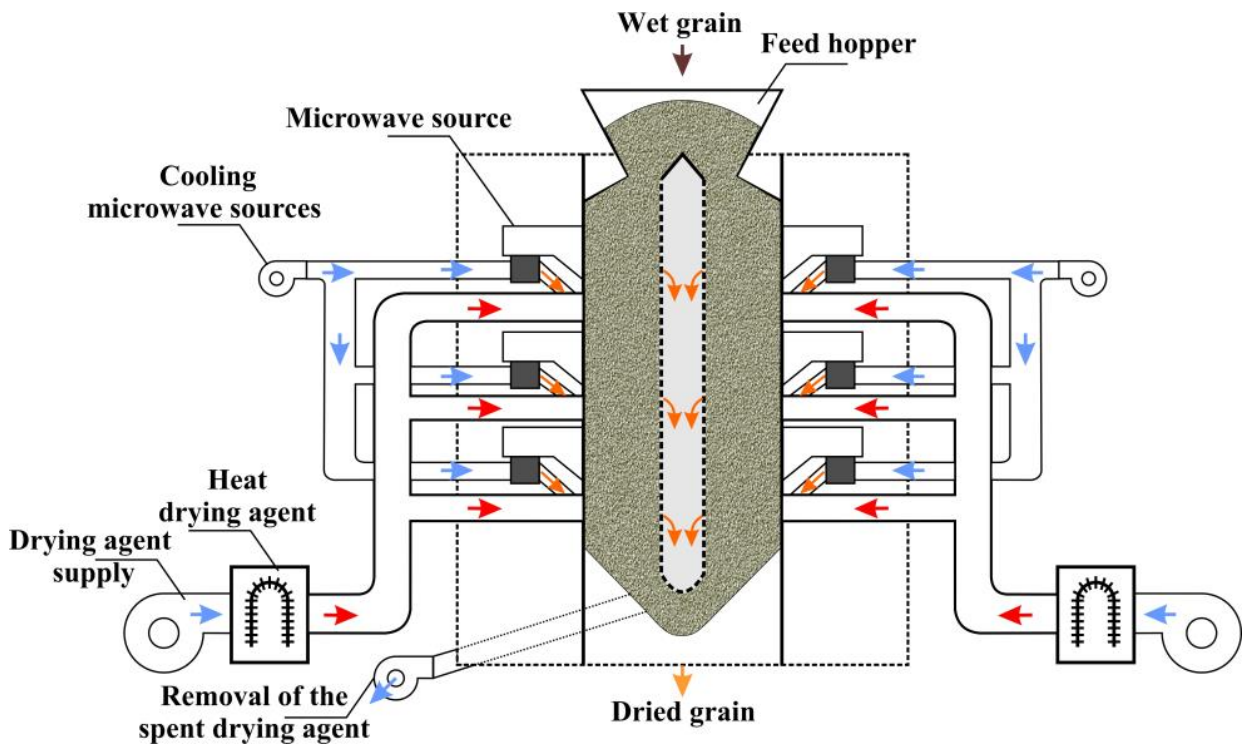

Fig. 1. The technological scheme of the laboratory installation.

Thus, the developed design of laboratory installation allows estimating the energy intensity and rate of grain drying processes using electrophysical factors and their combination at changing in a wide range of factors, such as product pipeline size, grain layer density, the combination of external intensifying influences, etc. Equipment operation modes, such as cycles of magnetrons switching on, rate of drying agent supply, required temperature of drying agent, as well as control of technological parameters and accumulation of statistical data, are controlled via the SCADA system. Data exchange and data logging is provided via MODBUS-RTU protocol. The installation and its control system were described in detail earlier [16].

\subsection{Experiment Design}

The following factors influencing the energy intensity of drying were considered: microwave power cycle during drying (ratio of microwave sources operation time to drying time); the drying agent temperature. The power-on time of magnetrons was set via the SCADA system and implemented by means of programmable relays. The cycle was 20 seconds. Thus, at the microwave power supply fraction of 0.25 the magnetron operated for 5 seconds, then it was switched off for 15 seconds and the cycle was repeated. The parameters of the experiment are given together with the results in Table 2.

Current moisture content was controlled both by an express method using the Fauna-M portable moisture meter and by sample sampling with subsequent measurement in laboratory conditions. It is worth noting that moisture meter readings with microwave field do not correspond to reality immediately after treatment due to the change in the form of bonding of liquid with a dry matter of grain. Equalization of moisture meter readings and indicators obtained in the laboratory occurs only after 30-40 minutes by the UHF treatment field. During the operation of the installation, the temperature of the grain layer in the immediate vicinity of the apertures of microwave power sources was monitored to avoid overheating of the grain above the temperatures regulated by the technological requirements. The monitoring was performed by OSMT-313 fiber optic temperature sensors. 


\subsection{Preferred Energy Sources}

Sources of solar, wind energy, biogas plants can be considered as sources of renewable energy, typical for agricultural enterprises and the regions in which they are located $[2,4]$. However, in the case of wind power plants, an additional stage of preconversion of electrical energy into thermal energy would be required to provide preparation of the drying agent, which could negatively affect the final energy balance.

Solar energy should be considered as the main in regions with a sufficient number of sunny days and the required intensity of solar radiation $[6,7]$. Researchers note the high efficiency of the use of solar energy for the preparation of the drying agent of various products, including grains of various crops. The application of these sources may be particularly interesting for cases where the crop is harvested at near conditioned moisture. This makes it possible to carry out the drying process over a longer period of time (several days) without additional costs for the intensification of the process. However, in many cases drying will need to be carried out on a tight schedule, which will somewhat limit the use of this type of energy.

Processing into biogas with its subsequent conversion into heat and electricity can be considered for livestock farms engaged in harvesting grain for fodder $[9,10]$. Since the accumulated waste from livestock products needs to be utilized, biogas synthesis processes have a high degree of relevance for livestock farms.

\section{Results}

Drying curves were taken to obtain the required data. After approximation of data by standard parametric model or by user-defined model, evaluation of approximation quality can be performed either graphically or by using different approximation suitability criteria: Rsquare, Adjusted R-square. In addition, confidence intervals for the found values of model parameters corresponding to different levels of probability and confidence bands for the approximation and data, also corresponding to different levels of probability, can be calculated. Dependence of change in grain moisture, $W, \%$, on drying time, $t$, min, can be represented by the following dependence:

$$
W=a \cdot e^{-b \cdot t}+c W_{3}=a_{e} \cdot e^{-b_{e} \cdot t_{\mathrm{cy}}}+c_{e},
$$

where $\quad a, b, c$ - model coefficients: $a, \% ; b, \min -1 ; c, \%$.

Table 2 shows the data obtained from the statistical processing of the drying curves.

Table 2. Parameters and results of the experiment.

\begin{tabular}{|c|c|c|c|c|c|}
\hline Mode & $\boldsymbol{a}$ & $\boldsymbol{b}$ & $\boldsymbol{c}$ & R-square & $\begin{array}{c}\text { Adj R- } \\
\text { square }\end{array}$ \\
\hline $\mathbf{1}$ & 3.438 & 0.0911 & 13.9 & 0.9819 & 0.9747 \\
\hline $\mathbf{2}$ & 3.769 & 0.07893 & 13.48 & 0.9836 & 0.9754 \\
\hline $\mathbf{3}$ & 3.293 & 0.09729 & 13.57 & 0.9996 & 0.9996 \\
\hline $\mathbf{4}$ & 3.035 & 0.05973 & 14.07 & 0.9911 & 0.9889 \\
\hline $\mathbf{5}$ & 3.013 & 0.04815 & 13.79 & 0,9864 & 0,9825 \\
\hline $\mathbf{6}$ & 3.332 & 0.07748 & 13.81 & 0.9745 & 0.966 \\
\hline $\mathbf{7}$ & 2.959 & 0.02602 & 13.95 & 0.9879 & 0.9855 \\
\hline $\mathbf{8}$ & 2.99 & 0.04361 & 13.96 & 0.9727 & 0.9666 \\
\hline $\mathbf{9}$ & 2.963 & 0.05021 & 13.92 & 0.9667 & 0.9584 \\
\hline
\end{tabular}


In further processing, schedules of moisture removal rate, energy consumption for moisture removal, as well as the ratio of electrical to thermal power required for plant operation were obtained. The results are presented in Table 3.

Table 3. Parameters and results of the experiment.

\begin{tabular}{|c|c|c|c|c|c|c|c|c|c|}
\hline Mode & $\mathbf{1}$ & $\mathbf{2}$ & $\mathbf{3}$ & $\mathbf{4}$ & $\mathbf{5}$ & $\mathbf{6}$ & $\mathbf{7}$ & $\mathbf{8}$ & $\mathbf{9}$ \\
\hline $\begin{array}{c}\text { Microwave power supply } \\
\text { cycle, o.u. }\end{array}$ & 0 & 0 & 0 & 0.25 & 0.25 & 0.25 & 0.5 & 0.5 & 0.5 \\
\hline Drying agent temperature, ${ }^{\circ} \mathrm{C}$ & 20 & 30 & 470 & 20 & 30 & 40 & 20 & 30 & 40 \\
\hline $\begin{array}{c}\text { Drying costs, MJ/kg of drying } \\
\text { capacity. }\end{array}$ & 6.17 & 6.8 & 8.57 & 6.1 & 7.59 & 4.64 & 4.36 & 3.74 & 3.4 \\
\hline Heat input, \% & 40 & 57 & 67 & 28 & 43 & 53 & 21 & 35 & 45 \\
\hline $\begin{array}{c}\text { Electrical power } \\
\text { consumption, \% }\end{array}$ & 60 & 43 & 33 & 72 & 57 & 47 & 79 & 65 & 55 \\
\hline of which UHF & 0 & 0 & 0 & 31 & 24 & 20 & 47 & 39 & 33 \\
\hline of which ventilation & 60 & 43 & 33 & 41 & 33 & 27 & 32 & 26 & 22 \\
\hline
\end{tabular}

It is worth noting that the drying process with the use of microwave power drying time is reduced by 2-3 times, which can intensify the processing of crops and reduce losses in case of untimely processing.

\section{Discussion}

The results obtained suggest that both the rate of moisture removal and the energy costs are significantly dependent on the mode of operation of the equipment, and on the initial and current moisture content of the material. Despite the fact that the current values of energy costs for moisture removal in regimes using microwave power may be higher than in regimes using heated air as the drying agent, the final costs for the entire drying process of these regimes are lower due to a significant reduction in drying time. It should also be taken into account that the use of pulsed microwave exposure modes is similar to the heating of the drying agent.

The ratio of electricity and heat costs suggests the possibility of using solar energy sources for the energy supply of these installations. The thermal energy will be used to prepare the drying agent and the electrical energy will be used to power the microwave power sources and drive the conveying devices. Obviously, in this case, stationary installations of relatively small capacity (less than 3 tons per hour) can be implemented. The electrical output will be $8-15 \mathrm{~kW}$.

Mobile installations based on commercially available pick-ups can also be implemented. The functional and technological diagram of such a device is shown in Fig. 2.

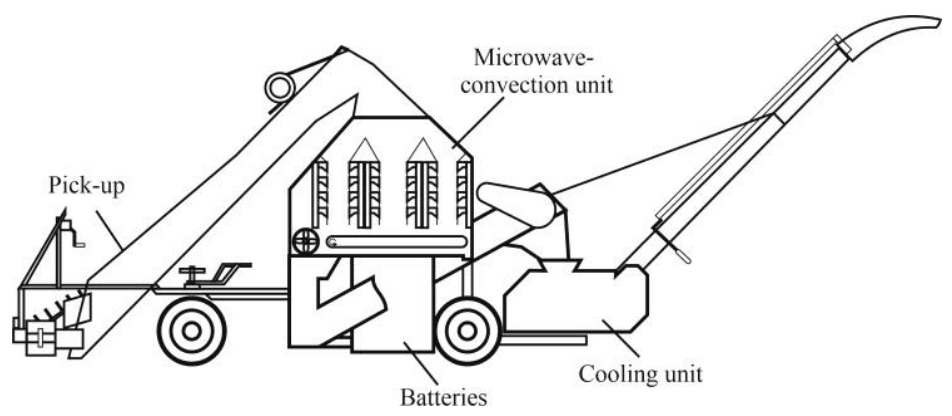

Fig. 2. The scheme of the mobile unit. 
In this case, it is possible to operate the mobile installation on the grain tank and it will be powered from batteries or by cable from the feeding unit.

Another option is the use of biogas installations. In contrast to solar installations, these ones are not dependent on weather conditions. They can be used at the enterprise as a source of thermal energy in the heating period, and for the energy supply of grain drying equipment in the warm period. In this case, the installation will be relevant primarily for livestock enterprises. The use of biogas plants in this case will reduce the cost of the final product, lower emissions into the atmosphere, waste processing, and disposal costs.

In addition to the process of microwave convective drying, the considered energy sources can be used in the processes of disinfection, micronization of grain, providing own household needs of the enterprise, and many others, which should be taken into account at the stage of designing or reconstruction of particular farms.

\section{Conclusion}

Based on the above, the following conclusions can be drawn:

- At the objects of agricultural production, it is reasonable to generate energy taking into account the full list of technological and household processes, as well as taking into account the ratio of required electric and thermal capacities.

- In the case of drying with the application of electrophysical influences, the share of electrical energy spent for technological process realization makes from 30 to $60 \%$.

- For the drying processes of cereal crops, it is advisable to use solar thermovoltaic plants and generators operating on biogas (taking into account the local generation of biogas from waste production).

- Application of energy generation sources on the basis of renewable types of energy makes it possible to provide power supply for stationary installations for primary processing and drying of grain.

\section{References}

1. X.F. Wang, P.P. Ma, Z.N. Wang. Scientometrics, 111 (2017).

2. W. Yunyang, W. Shaojin et al. Int J Agric \& Biol Eng, 4, 1 (2011)

3. K. Kupfer. Tm, 66, 6 (1999)

4. A.N. Vasil'yev, V.P. Goryachkina, D. A. Budnikov. IJEOE, 9, 2 (2020)

5. A.N. Vasil'yev, A.S. Dorokhov, D.A. Budnikov, A.A. Vasil'yev. AMA. 51, 3 (2020)

6. A.A. Mathew, T. Venugopal. International Journal of Ambient Energy, 42, 1 (2021)

7. E. Baniasadi, S. Ranjbar, O. Boostanipour. Renewable energy. 112, (2017)

8. P. Nesterenkov, V. Kharchenko. Advances in Intelligent Systems and Computing, 866 (2019)

9. M.A. Gladchenko, D.A. Kovalev, A.A. Kovalev, Yu.V. Litti, A.N. Nozhevnikova. Applied biochemistry and microbiology, 53, 2 (2017)

10. A.A. Kovalev, D.A. Kovalev, , V.S. Grigoriev. Engineering technologies and systems, 30, 1 (2020)

11. L. Appels, J. Baeyens, J. Degreve et all. PECS. 34, 6 (2008)

12. S.D. Varfolomeev, E. N. Efremenko, L.P. Krylova. Russian chemical reviews. 79, 6 (2010)

13. A.Y. Izmaylov, A.S. Dorokhov, V.S. Vershinin, et al. IJRER. 9, 1 (2019) 
14. V.A. Gusarov, Z.A. Godzhaev. Journal of machinery manufacture and reliability, 47, 6 (2018)

15. R. Ishikawa. J-Stage. 98, 10 (2019)

16. D.A. Budnikov, A.N. Vasil'yev. Advances in Intelligent Systems and Computing, 1072 (2020) 